\title{
New automated technique for assessing emphysema on histological sections
}

\author{
M Gillooly, D Lamb, ASJ Farrow
}

\begin{abstract}
The assessment of emphysema in human lungs has traditionally been based on observations made on whole lung slices. These methods are inappropriate for the study of early emphysema, because as much as $75 \%$ of the alveolar wall surface area may have been lost by the time airspaces are visible to the naked eye. $A$ new, automated image analysis system, the Fast Interval Processor (FIP), was used to measure airspace wall surface area per unit volume of lung tissue (AWUV). AWUV was measured on histological sections of lung tissue and expressed in $\mathrm{mm}^{2} / \mathrm{mm}^{3}$. The study sample consisted of resection specimens from 40 patients (32 men and 8 women whose ages ranged from 23-74 years). Histological sections from the inflated specimens were scanned using the FIP, and a mean AWUV value was calculated for each. The intra- and interobserver reproducibility of this method of measuring AWUV were examined. The results obtained using the FIP were also compared with those from an established image analysis system.

The FIP is a fast, efficient technique which gave highly reproducible results comparable with those obtained with an established and much more time consuming measuring technique.
\end{abstract}

Emphysema is defined as "a condition of the lung characterised by abnormal, permanent enlargement of airspaces distal to the terminal bronchiole, accompanied by destruction of their walls, and without obvious fibrosis".

Emphysema has traditionally been assessed by examining whole lung slices for the presence of macroscopically recognisable emphysema. ${ }^{2-7}$ By the time emphysematous spaces are visible to the naked eye, however, as much as $75 \%$ of the alveolar surface area may have been lost. ${ }^{8}$ Macroscopic assessments are therefore inappropriate for the study of early emphysema.

Various attempts have been made to assess the extent of early emphysema on histological sections, but the methods used have tended to be subjective and non-quantitative. ${ }^{9-11}$

The mean linear intercept $(\mathrm{Lm})$ has become the standard technique for measuring alveolar surface area on tissue sections, an approach intended to reflect the loss of respiratory tissue due to emphysema. ${ }^{2512-19}$ As Nagai et al repor- ted, however, ${ }^{11}$ in addition to being labour intensive, this is also a time consuming technique, taking an average of $\mathbf{4 5}$ minutes for one section.

Semiautomatic and automatic image analysis systems take much of the effort out of microscopic measurements of emphysema. These systems give accurate measurements on individual fields. The sampling procedure, however, is limited by the time taken to complete each measurement, usually around five minutes for a single histological field. ${ }^{2021}$

\section{Methods \\ THE TECHNIQUE}

The Fast Interval Processor (FIP) (fig 1) is a rapid scanning device which was developed by staff at the Medical Research Council Human Genetics Unit in Edinburgh. It is a prototype version of a scanner which is now commercially available as the "Cytoscan" (Image Recognition Systems, Warrington, Cheshire, England). The machine was originally designed as a prescreening device for cervical cytology specimens ${ }^{223}$ and has been adapted for use with lung tissue. The FIP uses the same approach as the mean linear intercept $(\mathrm{Lm})$ technique, whereby the number of intercepts of tissue with a test line is counted, and this figure is used to calculate the average distance between intercepts. A value for tissue surface area can be derived from $\mathrm{Lm}^{24}$

The FIP consists of a computer-linked Nikon inverted microscope equipped with a motorised stage and a Fairchild CCD linear image sensor. The sensor consists of a stationary array of photosensitive units which recognise the optical density pattern of the specimen. Each histological section is scanned electronically in the y-axis by the sensor at $10 \mu \mathrm{m}$ intervals. Sections are scanned mechanically in the $\mathrm{x}$-axis by moving the stage in $1 \mu \mathrm{m}$ steps. The scanning rate is $20001 \mu \mathrm{m}$ steps per second, so the stage moves continuously.

In total, an area of $121 \mathrm{~mm}^{2}$ is scanned on each histological section. As the stage is moved the section passes, and is scanned by, the stationary linear image sensor. The image obtained from the scan consists of a grid of picture elements or "pixels". A user-defined threshold limit determines which pixels are recognised as tissue pixels and which are background pixels. A size filter ensures that groups of thresholded pixels less than $6 \mu \mathrm{m}$ in diameter are ignored. This gets rid of most of the cells, debris, and background "noise" which may be thresholded. Contiguous groups of thresh- 


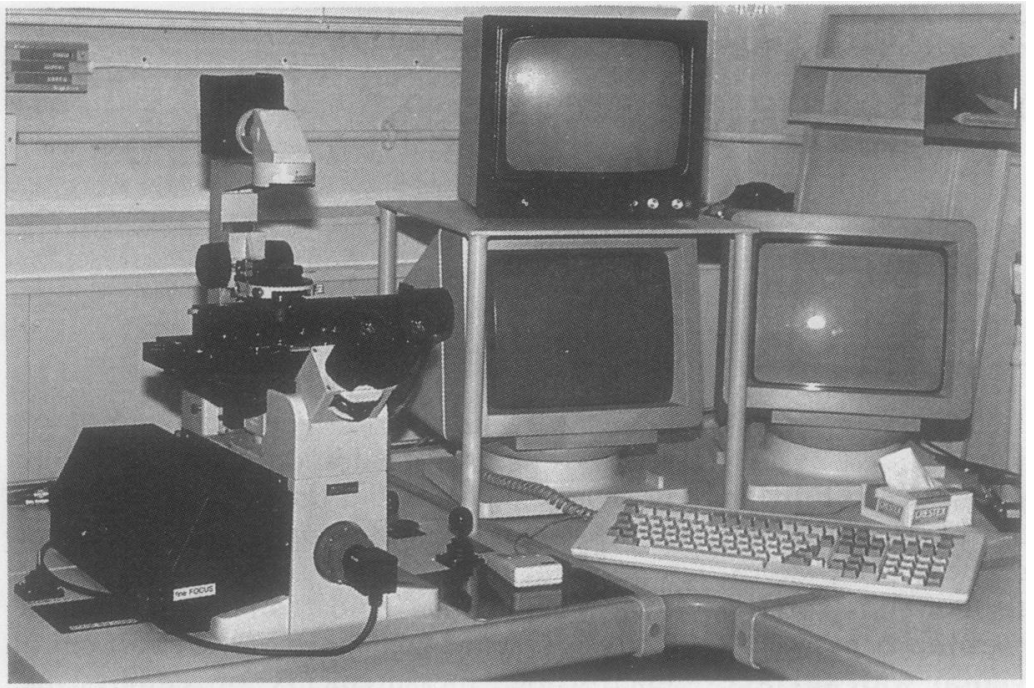

Figure 1 The Fast Interval Processor (FIP).

olded pixels in one scan line are treated together as "intervals". Intercepts with the electronic "test-line" and the start and end of each interval-that is, two intercepts for each interval-are recorded (fig 2).

For ease of calculation, intercept totals from each $1 \mathrm{~mm}^{2}$ field (unit area) are stored by the computer. Each electronic scan creates a "testline" $1 \mathrm{~mm}$ in length for each field, and as fields are scanned at $10 \mu \mathrm{m}$ intervals the total test-line length is $100 \mathrm{~mm}$ for each field (100 electronic scans $1 \mathrm{~mm}$ in length in each field). The mean linear intercept can thus be calculated:

$\mathrm{Lm}=$ total test-line length/total number of intercepts

As two intercepts have been counted for each airspace wall (interval) the formula for surface area is:

$$
\mathrm{SA}=2 \mathrm{~V} / \mathrm{Lm}^{24}
$$

Airspace wall surface area per unit volume (AWUV) is expressed in $\mathrm{mm}^{2} / \mathrm{mm}^{3}$ $\left(\mathrm{V}=1 \mathrm{~mm}^{3}\right)$. The formula thus becomes: AWUV $=2 / \mathrm{Lm}\left(\mathrm{mm}^{2} / \mathrm{mm}^{3}\right)$

Histological sections from 40 lungs were scanned using the FIP. The central coordinates of these sections were recorded using an England Finder Graticule (Graticules Ltd, Tonbridge, Kent, England) so that each $1 \mathrm{~mm}^{2}$ field could be relocated.
SAMPLING TECHNIQUE

Lungs or lobes were obtained from 40 surgical resections for peripheral tumours. Of these, 32 patients were male and eight were female, with ages ranging from 23 to 74 years. The resected lung or lobe (hereafter referred to as lobe, as in most cases the complete lung was not available for study) was immediately inflated with formol saline at $25 \mathrm{~cm} \mathrm{H}_{2} \mathrm{O}$ and fixed in formol saline for 24 hours, and then cut into $1 \mathrm{~cm}$ thick parasaggital slices. The lateral two slices were overlaid by a grid of $2 \mathrm{~cm} \times 2 \mathrm{~cm}$ squares on a transparent sheet, and six $2 \mathrm{~cm} \times 2 \mathrm{~cm}$ blocks were cut from each slice, using a table of random numbers to provide the coordinates of each block (fig 3). The blocks were then embedded in glycol methacrylate before being cut into $3 \mu \mathrm{m}$ thick sections and stained with haematoxylin and eosin.

TISSUE PROCESSING

The sections used in this study were initially prepared as part of a study of the dimensions of small airways. It was therefore important to ensure that the distortion of the tissue due to processing was kept to a minimum. For this reason, glycol methacrylate (GMA) was used as the embedding medium, as it had been shown to produce negligible shrinkage or compression. ${ }^{25} \mathrm{As}$ this processing method is extremely time consuming, however, (only two cases are processed in a week), and because small airway morphology was not a concern of this study, the possibility of using paraffin wax embedded tissue was examined.

Tissue sections from 12 of the 40 cases were available for studying the differences in results produced by embedding in paraffin wax or GMA. Each section was scanned routinely using the FIP, and two mean AWUV values calculated for each case-a GMA mean AWUV and a paraffin wax mean AWUV. The results from the paraffin wax sections were corrected for shrinkage as follows. The tissue block area was measured before processing and the area of the cut section measured after processing. The ratio of these measurements was used to compute the area shrinkage, and the square root of this gave the linear shrinkage. The reciprocal of this figure was used as the correction factor. All AWUV results from the paraffin wax embedded blocks were multiplied by the correction factor
Figure $2 A$

diagrammatic

representation of an FIP scan. (A) Sections are scanned mechanically in the $x$-axis using the motorised stage and electronically in the $y$-axis with the stationary linear image sensor. (B) The sensor scans the section at $10 \mu \mathrm{m}$ intervals, each electronic scan producing a test-line $1 \mathrm{~mm}$ in length.

(C) Intercepts with the test-line and tissue borders are recorded. (D) $A$ total of $1211 \mathrm{~mm}^{2}$ fields are scanned on each tissue section. The arrows indicate the direction of the mechanical scan.
Direction of stage movement

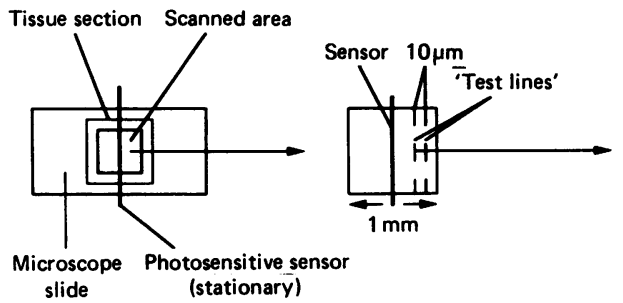

(A)

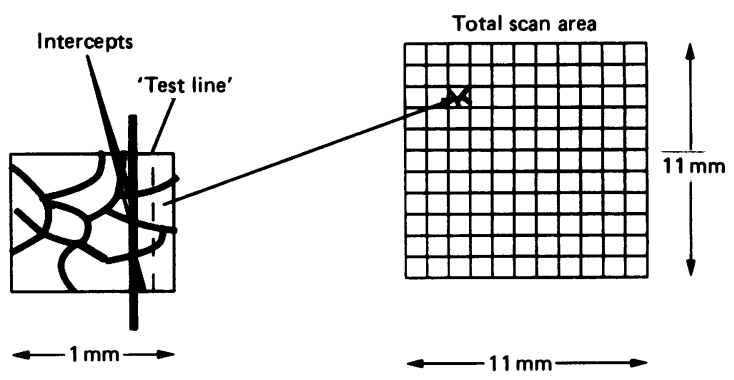

(D) 
Figure 3 The method of random sampling of blocks from the lung slices. $A 2$ $\mathrm{cm} \times 2 \mathrm{~cm}$ square grid was parasagittal slices cut from the fixed inflated specimen after resection. A table of random numbers was used to give the co-ordinates of the six blocks to be taken from each slice. overlaid on the lateral two

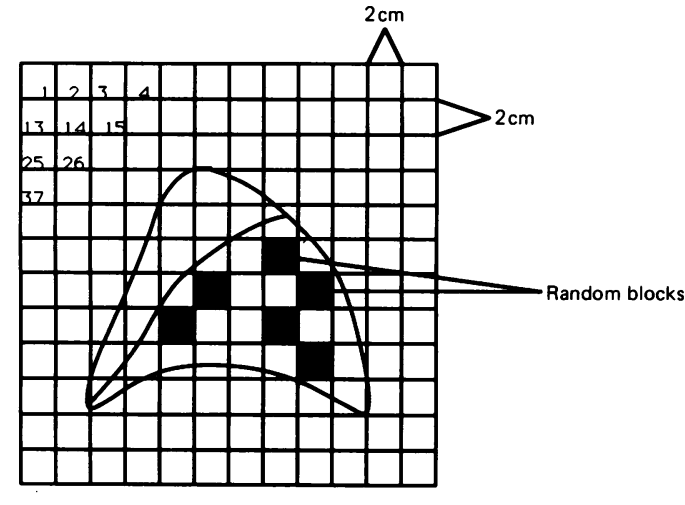

prior to comparison with the AWUVs from the GMA blocks. The correlation between the results using these two embedding media was then assessed.

COMPARISON WITH AN ESTABLISHED METHOD To test whether the AWUVs obtained using the FIP were comparable with the results of previous studies, the mean AWUV values of the 40 lobes were compared with the results for the same lobes using the IBAS2 semiautomatic image analysis system (Kontron Elektronik Ltd, Watford, Hertfordshire, England). This system has been used to measure AWUV in the past, and has been shown to give highly accurate and reproducible results. ${ }^{212627}$

\section{INTRAOBSERVER REPRODUCIBILITY}

Histological sections from 10 lobes were selected at random from the sample. These were scanned a second time, and the mean AWUV for each lobe compared with the mean AWUV from the first scan.

\section{INTEROBSERVER REPRODUCIBILITY}

Ten lobes were chosen at random from the total of 40 . These were scanned by a second observer, and the mean AWUV values obtained were compared with the results of the first observer. (The 10 lobes used for this comparison were not necessarily the same lobes which were used in the intraobserver reproducibility trial).

All statistical tests were carried out using the Minitab package.

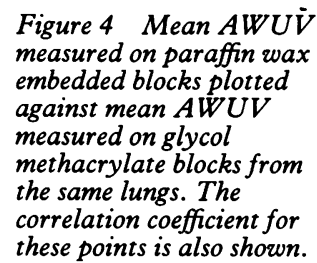

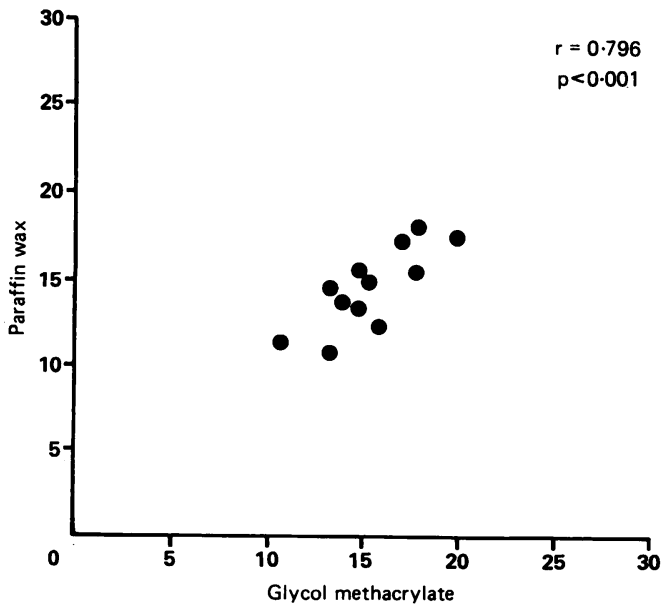

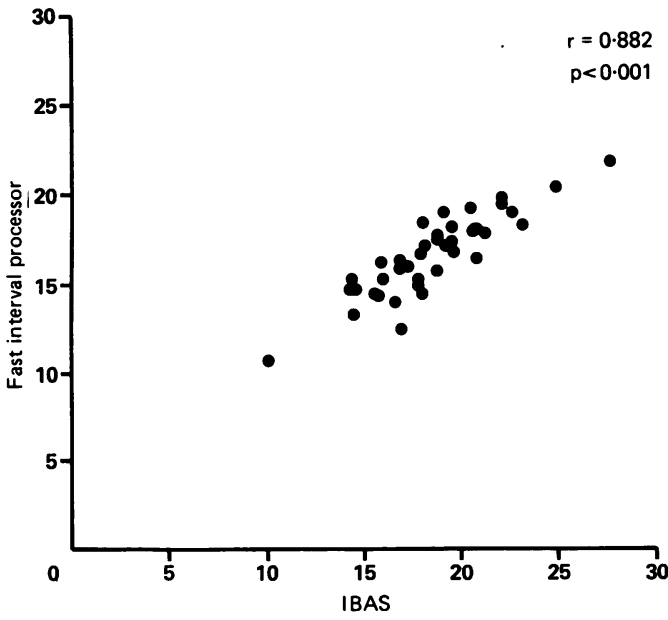

Figure 5 The mean AWUV from each lobe from the FIP is plotted against the mean AWUV obtained using the IBAS2. The correlation coefficient for these points is also shown.

\section{Results}

There was a strong correlation between the mean AWUVs from the paraffin wax and GMA embedded blocks $(r=0.796 ; \quad p<0.001)$ (fig 4).

There was a good correlation between the FIP results and the IBAS2 results $(r=0.882$; $\mathrm{p}<0.001)$. The mean AWUV values obtained by the two methods are plotted in fig 5 .

A high degree of correlation was found between the results of the first and second scans by the same observer $(r=0.995 ; p<0.001)$ and between the results of the FIP scans by two different observers $(r=0.984 ; p<0.001)$.

\section{Discussion}

The FIP gave comparable results using paraffin wax and GMA embedded tissue taken from the same cases when paraffin wax results were corrected for shrinkage. This result indicates that it is feasible to use paraffin wax embedded sections to measure the mean AWUV for a lung. Therefore, if the time available for tissue processing is limited, and if the measurement required is a single AWUV value for a lung, then tissue sections processed in paraffin wax are of adequate quality for use with the FIP, provided that shrinkage of the block is taken into consideration in the calculation of AWUV.

A high degree of correlation was found between the AWUV results from the FIP and those from the IBAS2, but the results from the two systems were not identical for two major reasons.

First, the two systems work on fundamentally different principles. IBAS2 results are based on very accurate measurements from small areas of lung. FIP results are based on morphometric estimates from wider areas of lung. Such estimates are likely to be more representative of the overall state of the lung, according to the principle of "do more less well", because the precision of an estimate is affected more by the number of sample images measured than by the precision with which the single image is measured. ${ }^{28}$ 
Figure $6 A$

diagrammatic

representation of the

differences in sampling

technique between the

IB $A S 2$ and the FIP. ( $A$

Using the IBAS2, three or four single $1 \mathrm{~mm}^{2}$ fields are selected at random from each section. ( $B)$ Using the FIP, $1211 \mathrm{~mm}^{2}$ fields are scanned on each section.

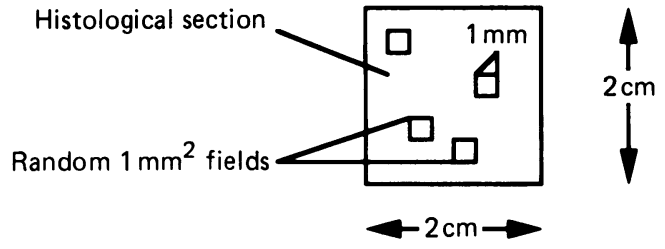

(A)

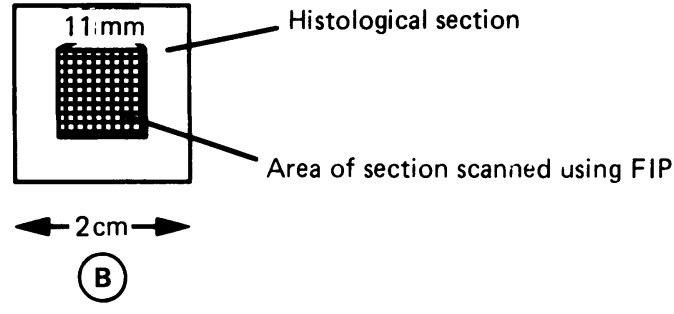

area on each section is one of the major advantages of the FIP. It is possible to relate the AWUV values for each individual field to the histological section and study the AWUV patterns, and hence the patterns of microscopic emphysema within a lobe or lung. (It should be noted that the size of the FIP scan can be altered according to the requirements of the operator. The area of $121 \mathrm{~mm}^{2}$ was adequate for the purpose of this study).

The other major advantage of the FIP is its speed. Scanning at a rate of $2 \mathrm{~mm}^{2}$ per second, 12 histological sections can be scanned in around 30 minutes, and much of this time is involved in positioning the microscope slides and setting threshold limits (the manual input). It is therefore possible to assess emphysema in a much larger number of cases than would have been feasible using a slower method.

We conclude that the FIP is a rapid scanning system which can be used to assess alveolar wall surface area in histological sections. It is a userfriendly device giving highly reproducible results which are comparable with those produced using an established image analysis system. The combination of its speed and the large number of fields analysed make the FIP a valuable method for assessing early emphysema in groups of subjects, and for investigating the patterns of early emphysema within the lung itself.

The FIP produced negligible intrainterobserver variation. The reproducibility is largely due to the high degree of automation of the system. This has its advantages and disadvantages. While it ensures the objectivity of the measurements, it also means that it is impossible to edit the image presented to the system. Because of this, sections from oedematous lungs or sections of poor quality are unsuitable for FIP analysis. This is especially a problem when dealing with lungs obtained at necropsy, where fluid and cellular infiltrate are often found in the alveoli. A degree of editing is possible, however, whereby intercept totals from fields which contain a large amount of cells or debris may be excluded from the results. This is done by identifying individual fields using their England-Finder coordinates, locating the results from these fields on the computer, and deleting them from the results file. Alternatively, sections which contain a large proportion of non-parenchyma may be excluded from the scan altogether.

It is feasible to edit out intercept totals from the results in this way because the area scanned in each section is so large. An area of $121 \mathrm{~mm}^{2}$ was scanned on each section in this study, leading to at least $10001 \mathrm{~mm}^{2}$ fields for each lobe, as opposed to an average of 30 fields using the IBAS2 (fig 6 ). The scanning of such a large
We thank Dr Malcolm Lang for his help with the interobserver Te thank Dr Malcolm Lang for his help with the interobserver reproducibility assessment. This study was

1 Report of the National Heart, Lung and Blood Institute. The definition of emphysema. Am Rev Respir Dis 1985 132:182-5.

2 Dunnill MS. Quantitative methods in the study of pulmonary pathology. Thorax 1962;17:320-8.

3 Dunnill MS. The recognition and measurement of pulmonary emphysema. Pathol Microbiol (Basel) 1970;35:13845 .

4 Ryder RC, Thurlbeck WM, Gough J. A study of interobserver variation in the assessment of the amount of pulmonary emphysema in paper-mounted whole lung pulmonary emphysema in paper-mounted
sections. Am Rev Respir Dis 1969;99:354-64.

5 Thurlbeck WM. Measurement of pulmonary emphysema Am Rev Respir Dis 1967(a);95:752-64.

6 Thurlbeck WM, Anderson AE, Janis M, et al. A cooperative study of certain measurements of emphysema Am Rev Respir Dis 1968;98:217-28.

7 Thurlbeck WM, Dunnill MS, Hartung W, Heard BE Heppleston AG, Ryder RC. A comparison of three methods of measuring emphysema. Human Pathol 1970 $1: 215-26$ Pathology. In: Brewis RAL, Gibson GJ, Geddes DM eds. Respiratory Medicine. London: Balliere Tindall, 1990:497-506.

9 Saetta M, Shiner RJ, Angus GE, et al. Destructive Index: A measurement of lung parenchymal destruction in smokmeasurement of lung parenchymal des "Destructive Index" in nonemphysematous and emphy"Destructive Index" in nonemphysematous and emphy-

11 Nagai A, Yamawaki I, Thurlbeck WM, Takizawa T. Assessment of lung parenchymal destruction by using routine histologic tissue sections. Am Rev Respir Dis 1989;139: 313-19.
8 Lamb D. Chronic obstructive pulmonary disease (COPD)-

10 Saito K, Cagle P, Berend N, Thurlbeck WM. The 
12 Bignon J, Khoury F, Even P, Andre J, Brouet G. Morphometric study in chronic obstructive pulmonary disease. Am Rev Respir Dis 1969;99:669-95.

13 Depierre A, Bignon J, Lebeau A, Brouet G. A quantitative study of parenchyma and small conductive airways in chronic nonspecific lung disease. Chest 1972;62:699-708.

14 Duguid JR, Young A, Cauna D, Lambert MW. The internal surface area of the lung in emphysema. J Clin Pathol 1964;88:405-21.

15 Dunnill MS. Evaluation of a simple method of sampling the lung for quantitative histological analysis. Thorax lung for quanti

16 Hansen JE, Ampaya EP. Human air space shapes, sizes, areas and volumes. $J$ Appl Physiol 1975;38:990-5.

17 Hasleton PS. The internal surface area of the adult human lung. J Anat 1972;112:391-400.

18 Thurlbeck WM. The internal surface area of nonemphysematous lungs. Am Rev Respir Dis 1967(b);95: 765-73.

19 Thurlbeck WM. Internal surface area and other measurements in emphysema. Thorax 1967(c);22:483-96.

20 McCartney AC, Fox B, Partridge TA, et al. Emphysema in the blotchy mouse: a morphometric study. J Pathol 1988;156:77-81.
21 Gould GA, MacNee W, McLean A, et al. CT measurements of lung density in life can quantitate distal airspace enlargement-an essential defining feature of human emphysema. Am Rev Respir Dis 1988;137:380-92.

22 Shippey G, Bayley R, Farrow S, Lutz R, Rutovitz D. A fast interval processor (FIP) for cervical prescreening. Anal Quant Cytol 1981;3:9-16.

23 Tucker JH, Shippey G. Basic performance tests on the CERVIFIP linear array prescreener. Anal Quant Cytol 1983;5:129-37.

24 Aherne WA, Dunnill MS. Morphometry. London: Edward Arnold, 1982:46-59.

25 McLean A, Lamb D. Morphometry of small airways in man. J Pathol 1983;141:520.

26 Lamb D, McLean A Flenley DC. A new technique for measuring alveolar surface area and the assessment of microscopic emphysema. Thorax 1986;41:716.

27 McLean A, Lamb D, Gould G, Warren P, Flenley DC. Morphometric factors associated with airflow limitation in early COAD. Thorax 1987;42:210

28 Gunderson HJG, Osterby R. Optimising sampling efficiency of stereological studies in biology. $J$ Microsc 1981;121:65-73. 